\title{
Improving Cultural Competency: A Patient-Centered Approach to Interprofessional Education and Practice in a Veterans Healthcare Facility
}

\author{
Dr. Margaret Brommelsiek ${ }^{1}$, Ph.D., Jane A. Peterson ${ }^{2}$, Ph.D., RN, APRN, FAANP, \& Sarah Knopf Amelung ${ }^{3}$, MA \\ ${ }^{1}$ Director of Interprofessional Education Health Sciences Schools, Associate Research Professor, University of \\ Missouri Kansas City-SoNHS, 2464 Charlotte Kansas City, MO 64108, USA \\ ${ }^{2}$ Clinical Associate Professor, University of Missouri Kansas City-SoNHS, 2464 Charlotte, Kansas City, MO 64108, \\ USA \\ ${ }^{3}$ Research Associate, University of Missouri Kansas City-SoNHS, 2464 Charlotte, Kansas City, MO 64108, USA \\ Correspondence: Dr. Margaret Brommelsiek, Ph.D., Director of Interprofessional Education Health Sciences Schools, \\ Associate Research Professor, University of Missouri Kansas City-SoNHS, 2464 Charlotte Kansas City, MO 64108, \\ USA.
}

Received: July 26, 2018

doi:10.5430/ijhe.v7n4p157
Accepted: August 14, 2018

Online Published: August 15, 2018

URL: https://doi.org/10.5430/ijhe.v7n4p157

\begin{abstract}
Background/Objective: Competency in health professions education when separated from culture is a 'detached mastery' of a discreet skill; there are no values considered, no human behind the understanding. This can result in an uneven understanding, proficiency, and commitment concerning individuals' cultural differences. To increase cultural competency and improve care delivery to veterans, health professional students, participated in an interprofessional education immersion with clinical practicum at a Veteran's Administration primary care clinic.
\end{abstract}

Methods: Fifty-four graduate students from nursing, clinical psychology, pharmacy and social work participated in an interprofessional education course on military culture. Students' knowledge and attitudes concerning veterans were evaluated at the start and end of the 8-week immersion course.

Results: In both the Knowledge Assessment, a 10-item survey covering the core aspects of the course content, and Health Professionals' Attitudes Toward Veterans Scale, student knowledge and attitudes improved relating to veterans care.

Conclusions: Veterans seeking care in veterans' and civilian facilities require a culturally competent health professional workforce. Interprofessional education coursework specifically focused on veterans and military culture has shown promise in increasing knowledge and compassion in health professional students working with veteran patients.

Keywords: military culture, veteran's health, interprofessional education, teamwork

\section{Background and Significance}

Cultural competency in health professions education is one way in which healthcare professionals become better versed concerning the needs and values of a diverse patient population. This has entailed exposure to various populations as a means for acquiring an increased understanding of cultural differences and similarities for addressing health disparity (Betancourt, 2003). While such efforts serve to advance knowledge about differences among various cultures, often missing, is how best to foster deeper engagement as health professionals and to develop respect and understanding of the power health professionals unknowingly may exercise over various populations in society (Tervalon \& Murray-Garcia,1998). Two reports, Crossing the Quality Chasm (2001) and Unequal Treatment (2003), published by the Institute of Medicine (IOM) called attention to the need for greater patient involvement in healthcare and an increase in cultural understanding to decrease bias and improve access to care. Despite the focus on an increased need to provide cultural competency training across the health professions, a widely accepted and conclusive cultural competency framework does not yet exist (Truong, Paradies \& Priest, 2014). 
Defining culture is not easy, particularly, what entails competency concerning cultural understanding in the health professions. One definition is to view culture as the behaviors and beliefs of shared or agreed upon thoughts, communication, and interactions among members of a group, coupled with values, practices, and customs (Robins, Fantone, Hermann, Alexander, \& Zweitfler, 1998; Donini-Lenhoff \& Hedrick, 2000). Culture may be defined as commonalities in beliefs, intentions, and morals that delineate a group of people (House, Javidan, Hanges, \& Dorfman, 2002), while Schwartz (1999), views cultural values a collective of ideas held within a society.

According to Nunez (2000), every individual is shaped by culture because it provides the lens from which persons understand the world in terms of values and beliefs (Hitckcock et al, 1999). For patients, culture affects the overall experience, serving as a guide for coping with feelings and informing them how to describe and explain an illness event (Gayer-Berenson, 2011). This is because culture helps to shape individuals' concepts of illness along with the meanings attached to changes in health status (Kosoko-Lasaki et al, 2009). From a systems perspective, all health professionals belong to a professional subculture (Helman, 2000), with each profession having its own language and views of both health and the illness experience of patients (Kosoko-Lasaki, 2009). Thus, it is within these cultures that health professions students, through their formal and informal education, acquire cultural knowledge and begin to develop personal beliefs.

Competency in health professions education when separated from culture is a 'detached mastery' of a discreet skill because there are no values considered, no human behind the understanding. However, intentional cultural competency training, the focus is on the nontechnical humanistic skills that include both empathy and a willingness to be open to the values and beliefs of others (Seeleman et al, 2009). While acknowledged that health professionals must be culturally competent for serving a growing diverse patient population, the majority of cultural competency training has been situated within specific professional schools rather than offered collectively across the health professions (Jirwe, Gerrish, Keeney, \& Emami, 2009; Purnell, 2002; Mostow et al., 2010; Perloff, Bonder, Ray, Ray, \& Siminoff, 2006; Qureshi, Collazos, Ramos, \& Casas, 2008).

Training students to be culturally competent encompasses several broad-reaching goals: an awareness of the relationship between cultural beliefs and behaviors toward improved care delivery to diverse populations, and enhanced provider-patient interactions through better communication skills (Betancourt, Green, Carillo, \& Park 2005). According to Beach et al (2005), cultural competency training is an important approach to facilitate healthcare provider's attitudes and reduce provider bias in support of patient-centered care. Thus, to be culturally competent within healthcare one must possess an ability to respect another's behaviors and beliefs. (Cross, Bazron, Dennis, and Isaacs, (1989).

Interprofessional Education (IPE) and Interprofessional Clinical Practice (IPCP) (IPEC, 2011; Pecukonis, Doyle \& Bliss, 2008) are ideal environments for teaching future health professionals to be culturally competent. While some health professions have specific courses devoted to cultural competency, others only integrate these concepts into other required coursework. This has resulted in an uneven understanding, proficiency, and commitment across the health professions concerning cultural differences of the individuals they will encounter as practicing clinicians. IPE and IPCP as part of health professions training offers opportunities to learn about and from one another and to develop a cultural framework of shared beliefs, coupled with the attainment of skills necessary for addressing cultural differences and ways in which to serve as advocates for patients both individually and as members of integrated teams.

Two of the IPE (IPEC, 2011) core competencies, Ethics/Values and Interprofessional Communication, have objectives that align with discussions around cultural differences and the need to be open to the values and beliefs of others. In participating as members of IPCP teams in a clinical setting, health professions students experience rich lessons in negotiating conflicts around patient and team values. Such exposure also allows for putting into practice moral reasoning that leads to critical thinking and creative problem solving. When students are encouraged to be self-reflect concerning others who differ from themselves, important insight can be acquired in promoting respectful healthcare delivery.

Cultural humility requires a continuing commitment to self-reflect concerning others (Tervalon \& Murray-Garcia, 1998). Achieving this goal would require training health professions students to view themselves as advocates and community partners on behalf of their patients. Truly affecting change within the healthcare delivery system calls for health professionals that understand the social determinants impacting health, the ways in which social stratification creates alienation and stigmatization among various cultures, and recognition of the role that each individual plays in the larger healthcare environment. 
Ethnocentrism can be defined as one's own morals as superior to an others beliefs (Thiederman, 1986). When practiced in the clinical setting, such a limited view can create barriers to the delivery of culturally sensitive care and may lead to unfounded assumptions. According to the Task Force Report on Spirituality, Cultural Issues, and End of Life Care (1999), what one believes and practices influences the way in which patients and healthcare professionals perceive an illness experience, and ultimately, the way in which they will interact with one another. This level of cultural openness in health professions education would require adopting what Dogra \& Kahlid (2005) termed cultural sensibility, a deep understanding of self, coupled with acknowledgement of the unique attributes that an individual brings in their role as a healthcare provider. This level of cultural awareness is an ability to appreciate and recognize distinctions in characteristics of individuals served. To develop these skills necessitates to momentarily disregard one's own values in order to reflect on the values of others.

Self-reflection is a teachable skill (Lew \& Schmidt, 2011) that can assist health professions students to examine their own biases, values, and beliefs. Through reflection of self, health professions students may be better equipped to learn to appreciate the value of others, an important component in helping to close the gap in healthcare access and inequity. Developing this ability helps to shift the attention to the individual, rather than on a particular culture or group of individuals.

This paper discusses one mid-western university's interprofessional education project with clinical practicum at a Veteran's Administration (VA) primary care clinic designed to increase cultural competency among graduate health professional students in nursing, pharmacy, social work and clinical psychology.

\subsection{Cultural Competence}

The foundation of patient-centered care is a consideration of the patient as a unique individual. According to Camphina-Bacote (2011), cultural competence and patient-centeredness need to be viewed as one in the same, with cultural competence an expansion of the way in which healthcare providers regard and deliver care to patients. Beach et al (2005) concur with this view, as both patient-centeredness and cultural proficiency is tied to quality of care and healthcare equity. This cultural competence facilitates patient-centered care, by reducing health disparities and improving patient outcomes as social and cultural influences inform the ways in which patients view their own health (Betencourt, 2003; Betancourt, Green, Carillo, \& Park, 2005). This suggests that health professions students need to understand the important roles that patients, family members, and community health workers play in the healthcare equation. (Rutherford, G. (2011).

\subsection{Health Professions Students' Attitudes}

As noted previously, each health profession is its own unique culture (Kosoko-Lasaki, 2009). Therefore, culture directly influences the attitudes that health professions students' form during their education. For example, in a study that looked at nursing students pre-conceived attitudes toward individuals who were poor or homeless tended to harbor negative perceptions toward these patients, with some students revealing that they would decline care to homeless persons in certain situations (Zrinyi \& Balogh, 2004). Boylston and O'Rourke (2013), in a study examining disadvantaged populations and individual's attitudes found that negative attitudes toward these individuals contribute to barriers in access to care, yet exposure through clinical interactions with the same patient population revealed an increase in compassion. The attitudes of health professions students concerning the economically disadvantaged can occur within a larger context of cultural perspective, including social determinants affecting population health. In a study addressing medical students' perceptions of the poor, the authors identified three methods for improving cultural understanding: increasing socio-economic diversity among the student population, promoting empathy in curricular offerings, and role modeling by faculty coupled with critical reflection (Wear \& Kuczewski, 2008).

\subsection{Veterans Health}

Preparing future healthcare providers for working with a veteran patient population requires culturally competent individuals who fully understand the unique needs of these patients (Acosta, et.al, 2014). Such an understanding reaches beyond the patient to family members who may also be experiencing the aftermath of a loved one's service (Westphal \& Convoy, 2015; Center for Deployment Psychology, 2014). The military ethos instilled into service members, and termed, 'warrior ethos' refers to specific training received in preparation for combat and applies to all service members concerning scripted responsibilities that include loyalty, stoicism, excellence, courage, and selflessness (Westphal \& Convoy, 2015). Military ethos is a powerful influencer on one's values and beliefs that may affect recognition of symptoms and a reluctance to seeking help for medical conditions (Tanielian \& Jaycox, 2008).

Veterans comprise a diverse and distinct culture governed by codes, ethos, language, values and customs (Olenick, Flowers \& Diaz, 2016). A complex system, military function reflects the professional and cultural diversity of the 
country in which it is situated, with military ethos, the very foundation on which the organization lives and breathes, shaping one's behavior and serving as guide in the face of ethical decisions (Rochon \& Williams-Jones, 2016). Thus, complex systems such as the military create complex patients. As result of serving in this structure can be difficulty reintegrating into civilian life and a reluctance to seek care despite complex health issues that are both physiological and mental/behavioral. For example, one in four veterans receive a diagnosis of a mental/behavioral health disorder (NAMI, 2014). According to Murphy \& Fairbank (2013), some veterans may delay seeking treatment for their physical and psychological issues because they view it as a sign of weakness. In particular, veterans often have a reluctance to disclose mental/behavioral health issues, making diagnosis and treatment of veteran patients difficult. Veterans at highest risk for mental/behavioral health disorders are individuals who have more recently experienced combat (Taal, Vermetten, van Schaik, \& Leenstra, 2014). Mental/behavioral health disorder among veterans include depression, anxiety, post-traumatic stress disorder (PTSD), and Traumatic Brain Injury (TBI) (Hougsnæs, Bøe, Dahl, \& Reichelt, 2016; U.S. Department of Veterans Affairs, National Center for PTSD, 2016). Substance Use Disorder (SUD) is also prevalent among veterans with $22-40 \%$ of veterans from recent conflicts reporting a misuse of alcohol, with $10 \%$ off the veterans who sought care at a Veterans Health Administration facility diagnosed with alcohol misuse (Seal, et al., 2011). Each of these disorders is a complex health issue that requires competent and culturally sensitive care.

For women who have served in the military, there is a growing number dealing with military sexual trauma (MIT), with numbers ranging from 20\% to $71 \%$ (Baltrushes \& Karnik, 2013). MIT also carries both mental and physical pain that requires compassionate delivery of care. Helping health professions students to more fully understand as well as to appreciate, the health experiences of female veterans, is an important piece of improving healthcare delivery to this patient population.

Physical conditions are also high among all those who have served, with chronic pain affecting $82 \%$ of veterans (Johnson, Boudiab, Freunal, Anthony, Gmerek, and Carter, 2013) and amputations of a limb affecting thousands. A number of veterans experience both physical pain along with a mental/behavioral disorder, requiring management over time for treating these complex multiple chronic conditions.

\subsection{An IPE Immersion Project}

Through a HRSA-funded Advanced Nursing Education Practice grant, graduate students in nursing, pharmacy, social work, and clinical psychology participated in an interprofessional education immersion course with interprofessional collaborative practice at an urban VA primary care clinic. The purpose of the project was to increase students' knowledge and appreciation of the unique attributes of military culture and its influence on veteran patients. Attending sessions designed to increase knowledge concerning the unique issues of veterans. The immersion course provided specific content on military language and values, behavioral/mental health disorders and pharmacology for treating them, sexual trauma and the long-term consequences affecting patients, ethical reasoning, teamwork, and communication. Case-study scenarios specific to veteran's care needs were adapted for use in both classroom discussions and working with standardized patients. Faculty teaching the immersion modeled behaviors appropriate for working with a veteran patient population, serving as facilitators for the interprofessional student teams.

\section{Methods}

\subsection{Course Participants}

Students from nursing, clinical psychology, pharmacy and social work graduate programs were invited to participate in this learning experience. Fifty-four students (Table 1) agreed to participate across four semesters of the course. There were $22(40.7 \%)$ nurse practitioner students, nine (16.7\%) pharmacy students, $10(18.5 \%)$ clinical psychology students, and $13(24.1 \%)$ social work students. Over $70 \%$ identified as white and $82.4 \%$ were female. The average age of participants was 31.5, ranging from 23 to 54 years. All participants completed pre and post surveys (100\% follow-up rate). 
Table 1. Student Demographics

\begin{tabular}{ll}
\hline & $\%(\mathrm{n})$ \\
\hline Race/Ethnicity (select all that apply) & $0 \%(0)$ \\
Alaska Native & $7.8 \%(4)$ \\
American Indian & $11.8 \%(6)$ \\
Asian & $11.8 \%(6)$ \\
Black or African American & $3.9 \%(2)$ \\
Hispanic & $0 \%(0)$ \\
Native Hawaiian or other Pacific Islander & \\
White & $70.6 \%(36)$ \\
$\quad$ No Answer & $5.6 \%(3)$ \\
Gender & \\
Female & $82.4 \%(42)$ \\
Male & $17.6 \%(9)$ \\
$\quad$ No Answer & $5.6 \%(3)$ \\
Age & \\
$20-29$ & $51.9 \%(28)$ \\
$30-39$ & $22.2 \%(12)$ \\
$40-49$ & $18.5 \%(10)$ \\
$50-59$ & $1.9 \%(1)$ \\
No Answer & $5.6 \%(3)$ \\
\hline
\end{tabular}

\subsection{Survey Instruments}

The course was evaluated using pre-post survey instruments assessing the immersion experience's impact on student knowledge and attitudes toward veterans. Evaluation occurred at the start and end of the immersion experience. A Knowledge Assessment developed for this project was used to evaluate the core competencies to be learned in the immersion. This 10-item assessment tool measured learning of military culture, interprofessional teamwork, pharmacology, and behavioral and physical health assessment and management.

Participants also completed the Health Professionals' Attitudes Toward Veterans Scale (HPATV; Knopf-Amelung, Brommelsiek, Peterson, Roman, \& Graybill, 2018) before and after the course. The HPATV measures health professionals' attitudes regarding military cultural sensitivity and awareness (Culture subscale), provision of care to veteran patients (Care subscale), and the prominent veterans' health issues (Health subscale). See table 2 for instrument items.

\subsection{Analysis}

Data was entered and analyzed using IBM SPSS Statistics version 22. Descriptive statistics were generated, including means (standard deviations) and counts (percentages). To evaluate change in attitudes and knowledge, paired samples $t$-tests were conducted.

\section{Results}

Following the immersion course, students demonstrated a significant improvement in knowledge of course curriculum regarding military culture and veterans' health (mean [SD] pre-course $=6.02[1.25]$, post-course $=6.94$ [1.06], $p=.000$ ). Analysis of the HPATV showed a significant improvement in students' positive attitudes toward veterans across all domains of the HPATV (Table 2). Positive attitudes improved relating to knowledge and comfort with military culture (Culture subscale; mean [SD] pre-course $=7.46$ [2.92], post-course $=10.31[2.06], p=.000$ ), professional capacity and intention to provide evidence-based and culturally competent services to veterans (Care subscale; mean $[\mathrm{SD}]$ pre-course $=19.25[4.33]$, post-course $=23.19[3.75], p=.000$ ), and views toward prevalent veterans' health issues (Health subscale; mean [SD] pre-course $=17.96$ [3.33], post-course $=20.31$ [2.94], $p=.000$ ). 
Table 2. HPATV Item Pre- and Post-Course Means and Standard Deviations

\begin{tabular}{|c|c|c|c|c|}
\hline \multirow[t]{2}{*}{ HPATV Item } & \multicolumn{2}{|c|}{$\begin{array}{l}\text { Pre-Course } \\
\mathrm{n}=54\end{array}$} & \multicolumn{2}{|c|}{$\begin{array}{l}\text { Post-Course } \\
\mathrm{N}=54\end{array}$} \\
\hline & $\mathrm{M}$ & SD & M & $\mathrm{SD}$ \\
\hline $\begin{array}{l}\text { 1. I have sufficient knowledge of differences between military eras } \\
\text { (e.g., Vietnam era vs. Iraq/Afghanistan era) that may impact Veterans' } \\
\text { health. }\end{array}$ & 2.47 & 1.08 & 3.86 & .601 \\
\hline $\begin{array}{l}\text { 2. I routinely ask Veterans about the community-based services they } \\
\text { may need (e.g., housing, vocational services). }\end{array}$ & 2.73 & 1.13 & 3.82 & .962 \\
\hline $\begin{array}{l}\text { 3. I am uncomfortable talking to Veterans about possible symptoms of } \\
\text { post-traumatic stress disorder (PTSD) including nightmares and feeling on } \\
\text { guard. }\end{array}$ & 3.65 & 1.23 & 3.88 & 1.28 \\
\hline $\begin{array}{l}\text { 4. I am comfortable discussing alcohol and drug use with Veteran } \\
\text { patients. }\end{array}$ & 3.74 & 1.05 & 4.43 & .575 \\
\hline 5. I routinely screen patients for a history of military service. & 2.75 & 1.11 & 3.66 & 1.06 \\
\hline $\begin{array}{l}\text { 6. I am comfortable asking a Veteran for permission to discuss health } \\
\text { issues related to their military service. }\end{array}$ & 3.8 & .987 & 4.45 & .503 \\
\hline $\begin{array}{l}\text { 7. I feel comfortable asking Veterans about sexual harassment or sexual } \\
\text { trauma they may have experienced while serving in the military. }\end{array}$ & 3.08 & 1.11 & 3.88 & .864 \\
\hline $\begin{array}{l}\text { 8. I need more training on military culture to feel comfortable working } \\
\text { with Veterans. }\end{array}$ & 2.18 & 1.07 & 3.22 & .966 \\
\hline $\begin{array}{l}\text { 9. I have sufficient knowledge of post-traumatic stress disorder (PTSD) } \\
\text { triggers that could occur in a Veteran's daily life. }\end{array}$ & 3.22 & 1.03 & 4.00 & .800 \\
\hline 10. I plan to stay current on the literature regarding Veteran health issues. & 4.02 & .707 & 4.32 & .768 \\
\hline $\begin{array}{l}\text { 11. I am not familiar with the resources and services available to } \\
\text { Veterans. }\end{array}$ & 2.82 & 1.09 & 3.78 & .789 \\
\hline $\begin{array}{l}\text { 12. I feel more comfortable working with non-Veteran patients than } \\
\text { Veteran patients. }\end{array}$ & 3.08 & .997 & 3.53 & .946 \\
\hline $\begin{array}{l}\text { 13. Sometimes I feel I do not relate well to Veteran patients due to my } \\
\text { lack of military experience. }\end{array}$ & 2.75 & 1.29 & 3.27 & 1.10 \\
\hline $\begin{array}{l}\text { 14. I try not to make assumptions about how a Veteran views their } \\
\text { military experience. }\end{array}$ & 4.33 & .554 & 4.35 & .779 \\
\hline
\end{tabular}

*Care scale is items 2, 5-6, 10-12; Culture scale is items 1, 8, 13; Health scale is items 3-4, 7, 9, 14

\section{Discussion}

In healthcare, culturally proficient providers will remain crucial for meeting the needs of a growing diverse patient-population. The term culture encompasses multiple layers of interconnected parts with characteristics ranging from race to a litany of belief systems and practices. Therefore, health professionals must understand the intricacies of culture in serving patient needs.

The interprofessional education project described in this paper sought to prepare health professions students to work more closely with veterans and their family members. Much like culture, veterans needs can be complex, especially when a veteran is dealing with both a physical and mental disorders. Through providing students with discreet skills for working with veterans as a part of their formal education, health professionals working in nursing, pharmacy, social work and clinical psychology will be better equipped because they will more fully understand veterans' values and belief systems coupled with a working knowledge of military language for increased communication. Because a growing number of veterans are choosing to seek care through clinics outside of the VA, preparing future health professionals, especially those planning to work in primary care, will assist with improved access to health care for this population who may otherwise hesitate in seeking care due to cultural difference. 
Student participants in the IPE immersion and clinical practicum reported changes concerning veteran need and personal knowledge. Growth in student knowledge occurred through increases in comfort levels working with veterans, taking care not to make assumptions, greater comprehension of the differences in veterans in relation to the years served, with students' also reporting plans to stay current on veterans' health concerns once in professional practice.

Lessons learned through this IPE project include making course content on military culture relevant to the patient population served through the IP practicum and providing real-life examples of the lived experiences of veterans. Hearing first-hand through a veterans' panel helped to instill in students, the complexities of not only of a veteran's health, but also the ethos that inform veteran behavior and its impact long after an individual's tour has ended.

The limitations of this study include use of a newly developed and minimally tested instrument, occurrance at one university, and a relatively small sample size. However, this project provided training in cultural competence for health professional students helping to prepare them for providing care for veterans.

\section{Conclusion}

As military conflicts continue, the number of veterans re-integrating into civilian life will grow. Veterans seek healthcare in veterans' and civilian facilities, requiring a culturally competent health professional workforce for serving this complex patient population. An Interprofessional education immersion course focusing on veterans and military culture has shown promise in increasing the compassion and skill for health professional students working with veterans.

\section{Acknowledgments}

This IPE training module was made possible through a grant from the Human Resources Services Administration (HRSA), an operating division of the U.S. Department of Health and Human Services, Grant Number D09HP26956.

\section{References}

Acosta, J. D., Becker, A., Cerully, J. L., Fisher, M. P., Martin, L. T., Vardavas, R., \& Schell, T. L. (2014). Mental health stigma in the military. Santa Monica, CA: RAND Corporation. https://doi.org/10.7249/RR426

Baltrushes, N. \& Karnik, N.S. (2013). Victims of military sexual trauma, you see them, too. The Journal of Family Practice, 62(3), 120-125.

Beach, M. C., Price, E. G., Gary, T. L., Robinson, K. A., Gozu, A., Palacio, A., Smarth, C., Jenckes, M.W., Feuerstein, C., Bass, E.B., Powe, N. R., \& Copper, L.A. (2005). Cultural competency: A systematic review of health care provider educational interventions. Medical care, 43(4), 356. https://doi.org/10.1097/01.mlr.0000156861.58905.96

Betancourt, J. R. (2003). Cross-cultural medical education: Conceptual approaches and frameworks for evaluation. Academic Medicine, 78(6), 560-569. https://doi.org/10.1097/00001888-200306000-00004

Betancourt, J. R., Green, A. R., Carrillo, J. E., \& Park, E. R. (2005). Cultural competence and health care disparities: key perspectives and trends. Health affairs, 24(2), 499-505. https://doi.org/10.1377/hlthaff.24.2.499

Boylston, O'Rourke, R. (2013). Second-degree bachelor of science in nursing students' preconceived attitudes toward the homeless and poor: A pilot study. Journal of Professional Nursing, 29(5), 309-17. https://doi.org/10.1016/j.profnurs.2012.05.009

Brach, C. \& Fraseriector, I. (2000). Can cultural competency reduce racial and ethnic health disparities? A review and conceptual model. Medical Care Research and Review, 57(1), 181-217. https://doi.org/10.1177/1077558700057001S09

Brusin, J.H. (2011). How cultural competency can help reduce health disparities. Radiologic Technology, 84(2), $129-47$.

Campinha-Bacote, J. (2011). Delivering patient-centered care in the midst of a cultural conflict: The role of cultural competence. Journal of Issues in Nursing, 16 (2). doi: 10.3912/OJIN.Vol16No2Man05

Cross, T.L., Bazron, B. J., Dennis, K. W., \& Isaacs, M. R. (1989). Towards a culturally competent system of care: A monograph on effective services for minority children who are severally emotionally disturbed. Georgetown University Child Development Center, CASSP Technical Assistance Center, Washington, D.C.

Dogra, N. \& Khalid, K. (2005). Diversity training for psychiatrist. Advances in Psychiatric Treatment, 11(3), 159-169. https://doi.org/10.1192/apt.11.3.159 
Donini-Lenhoff, F. G., \& Hedrick, H. L. (1999). Increasing awareness and implementation of cultural competence principles in health professions education. Journal of Allied Health, 29(4), 241-245.

Dayer-Berenson, L. (2011) Cultural competencies for nurses: Impact on health and illness. Sudbury, MA: Jones \& Bartlett Learning.

Helman, C. G. (2000). Doctor patient interaction. In C. G. Helman (Ed.), Culture, health and illness: An introduction for health professionals (4th ed., pp.79-109). Boston: Butterworth Heinemann.

Hitchcock, J. H., Nastasi, B. K., Dai, D. Y., Newman, J., Jayasena, A., Bernstein-Moore, R., \& Varjas, K. (2005). Illustrating a mixed-method approach for validating culturally specific constructs. Journal of School Psychology, 43(3), 259-278. https://doi.org/10.1016/j.jsp.2005.04.007

Hougsnæs, S., Bøe, H.J., Dahl, A.A., \& Reichelt, J.G. (2016). Norwegian male military veterans show low levels of mental health problems four years after deployment in Afghanistan. Nordic Journal of Psychiatry, 29, 1-7. https://doi.org/10.1080/08039488.2016.1201529

House, R., Jarvidan, M., Hanges, P., \& Dorfman, P. (2002). Understanding cultures and implicit leadership theories across the globe: An introduction to project GLOBE. Journal of World Business, 37, 3-10. https://doi.org/10.1016/S1090-9516(01)00069-4

Institute of Medicine. (2001). Crossing the quality chasm: A new health system for the $21^{\text {st }}$ century. Washington, DC: The National Academies Press.

Institute of Medicine. (2003). Unequal Treatment: What healthcare system administrators need to know about racial and ethnic disparities in healthcare. Washington, DC: The National Academies Press.

Interprofessional Education Collaborative Expert Panel (2011). Core Competencies for Interprofessional Collaborative Practice: Report of an Expert Panel. Washington, DC: Interprofessional Education Collaborative.

Jirwe M., Gerrish K., Keeney S., \& Emami A. (2009). Identifying the core components of cultural competence: Findings from a Delphi study. Journal of Clinical Nursing, 18, 2622-2634. https://doi.org/10.1111/j.1365-2702.2008.02734.x

Johnson, B.S., Boudiab, L.D., Freunal, M., Anthony, M., Gmerek, G.B, \& Carter, J. (2013). Enhancing veteran-centered care: A guide for nurses in non-VA settings. American Journal of Nursing,113(7), 24-39. https://doi.org/10.1097/01.NAJ.0000431913.50226.83

Knopf-Amelung, S., Brommelsiek, M., Peterson, J.A., Roman, Z., \& Graybill, T.L. (2018). Developing a measure for health professionals' attitudes toward veterans. Journal of Nursing Education and Practice, 8(7), 60-67. https://doi.org/10.5430/jnep.v8n7p60

Kosoko-Lasaki, S., Cook, C. T., \& O'Brien, R. L. (2009). Cultural proficiency in addressing health disparities. Jones $\&$ Bartlett Publishers.

Lew, M. D., \& Schmidt, H. G. (2011). Self-reflection and academic performance: is there a relationship?. Advances in Health Sciences Education, 16(4), 529-545. https://doi.org/10.1007/s10459-011-9298-z

Purnell L. (2002). The Purnell model for cultural competence. Journal of Transcultural Nursing, 13, 193-196. https://doi.org/10.1177/10459602013003006

Mostow C., Crosson J., Gordon S., Chapman S., Gonzalez P., Hardt E., and David M.(2010). Treating and precepting with RESPECT: A relational model addressing race, ethnicity, and culture in medical training. Journal of General Internal Medicine, 25, 146-154. https://doi.org/10.1007/s11606-010-1274-4

Murphy, R.A. \& Fairbank, J.A. (2013). Implementation and dissemination of military informed and evidence-based interventions for community dwelling military and families. Clinical Child and Family Psychology review, 16(4), 348-364. https://doi.org/10.1007/s10567-013-0149-8

National Alliance for Mental Illness (NAMI). https://www.nami.org/find-Support/Veterans- Active Duty. Accessed: May 24, 2018.

Núñez, A. E. (2000). Transforming Cultural Competence into Cross-cultural Efficacy in Women's Health Education. Academic Medicine, 75(11), 1071-1080. https://doi.org/10.1097/00001888-200011000-00011

Olenick, M., Flowers, M. and Diaz, V.J. (2015). US veterans and their unique health issues: Enhancing health care professional awareness. Advances in Medical Education and Practice, 6, 635-639. https://doi.org/10.2147/AMEP.S89479 
Pecukonis, E., Doyle, O. and Bliss, D. (2015). Reducing barriers to interprofessional training: Promoting interprofessional cultural competence. Journal of Interprofessional Care, 22, 417e-428. https://doi.org/10.1080/13561820802190442

Perloff, R. M., Bonder B., Ray G. B., Ray E. B., Siminoff L. A. (2006). Doctor-patient communication, cultural competence, and minority health: Theoretical and empirical perspectives. American Behavioral Scientist, 49, 835-852. https://doi.org/10.1177/0002764205283804

Purnell, L. (2002). The Purnell model for cultural competence. Journal of Transcultural Nursing, 13(3), 193-196. https://doi.org/10.1177/10459602013003006

Qureshi A., Collazos F., Ramos M., Casas M. (2008). Cultural competency training in psychiatry. European Psychiatry, 23, 49-58. https://doi.org/10.1016/S0924-9338(08)70062-2

Robins, L. S., Fantone, J. C., Hermann, J., Alexander, G. L., \& Zweifler, A. J. (1998). Culture, communication, and the informal curriculum: Improving cultural awareness and sensitivity training in medical school. Academic Medicine, 73(10), S31-34. https://doi.org/10.1097/00001888-199810000-00037

Rutherford, G. (2011). Peeling the layers: A grounded theory of interprofessional co-learning with residents of a homeless shelter. Journal of Interprofessional Care, 25(5), 352-8. https://doi.org/10.3109/13561820.2011.576789

Seal, K.H., Cohen, G., Waldrop, A., Cohen, B.E., Maguen, S., \& Ren, L. (2011). Substance use disorders in Iraq and Afghanistan veterans in VA healthcare, 2001-2010: Implications for screening, diagnosis and treatment. Drug and Alcohol Dependence, 116(1), 93-101. https://doi.org/10.1016/j.drugalcdep.2010.11.027

Seeleman, C., Suurmond, J., \& Stronks, K. (2009). Cultural competence: a conceptual framework for teaching and learning. Medical education, 43(3), 229-237. https://doi.org/10.1111/j.1365-2923.2008.03269.x

Schwartz, S. H. (1999). A theory of cultural values and some implication for work. Applied Psychology, 48, 23-47. https://doi.org/10.1111/j.1464-0597.1999.tb00047.x

Tanielian, T., \& Jaycox, L. H. (Eds.). (2008). Invisible wounds of war: Psychological and cognitive injuries, their consequences, and services to assist recovery. Santa Monica, CA: RAND Corporation. Retrieved from fwww.rand.org/content/dam/rand/pubs/monographs/2008/RAND_MG720.pdf

Task Force on Spirituality, Cultural Issues, and End of Life Care (1999) Task Force report: spirituality, cultural issues and end of life care. In Report III Contemporary Issues in Medicine. Communication in Medicine (Eds. Association of American Medical Colleges). Washington DC.

Tervalon, M. and Murray-Garcia, J. (1998). Cultural humility versus cultural competency: A critical distinction in defining physician training outcomes in multicultural education. Journal of Health Care for the Poor and Underserved, 9(2), 117-125. https://doi.org/10.1353/hpu.2010.0233

Thiederman, S. B. (1986). Ethnocentrism: a barrier to effective health care. The Nurse Practitioner, 11(8), 52-59. https://doi.org/10.1097/00006205-198608000-00006

Truong, M., Paradies, Y., \& Priest, N. (2014). Interventions to improve cultural competency in healthcare: a systematic review of reviews. BMC health services research, 14(1), 1. https://doi.org/10.1186/1472-6963-14-99

U.S. Department of Veterans Affairs, National Center for PTSD. http://www.ptsd.va.gov/public/PTSD-overview/basics/how-common-is-ptsd.asp. Last updated October 3, 2016.

Wear, D. and Kuczewski, M.G. (2008). Perspective: Medical students' perceptions of the poor: What impact can medical education have? Academic Medicine, 83(7), 639-45. https://doi.org/10.1207/s15328015tlm1803_7

Westphal, R., Convoy, S., (2015). Military culture implications for mental health and nursing care, OJIN: The Online Journal of Issues in Nursing, 20(1), 47-54. https://doi.org/10.3912/OJIN.Vol20No01Man04

Zrinyi, M. and Balogh, Z. (2004). Student nurse attitudes toward homeless clients: A challenge for education and practice. Nursing Ethics, 11(4), 334-48. https://doi.org/10.1191/0969733004ne707oa 